Mal J Nutr 27(3): 421-431, 2021

\title{
Improving maternal nutrition in public health facilities by strengthening the dietary component of Janani Shishu Suraksha Karyakram - A government of India programme
}

\author{
Annie Kuruvilla ${ }^{{ }^{*}}$, Komal Panchasara ${ }^{1}$ \& Nilam Panchal ${ }^{2}$ \\ ${ }^{1}$ Department of Foods \& Nutrition, Faculty of Family \& Community Sciences, \\ Maharaja Sayajirao University, Vadodara, Gujarat, India; ${ }^{2}$ Population Research \\ Center, Department of Statistics, Faculty of Science, Maharaja Sayajirao University, \\ Vadodara, Gujarat, India
}

\begin{abstract}
Introduction: The Janani Shishu Suraksha Karyakram (JSSK) is a government of India initiative for all pregnant women visiting public health facilities, with many free entitlements - free diet being one. After an in-depth study of existing dietary provisions in all community health centres, an elaborate cyclic-weekly nutritious menu was designed taking into consideration the latest recommendations (2019) by the Ministry of Family and Child Welfare, India to improve maternal health nutrition. Methods: The health functionaries from all ten community health centres of rural Vadodara were chosen for an in-depth estimation of the different meals served in the facilities. Standard measuring cups and spoons were used to measure the exact serving sizes for each person. Each meal served was supervised, checked and quantified in triplicate, while macro- and micronutrients were calculated using the Indian Food Composition Tables 2017 (Longvah et al. 2017). To bridge the gap in service delivery, two new models of cyclic-weekly menu were developed, keeping in mind the amount per mother per day as one hundred Indian rupees. Results: On average the foods served in the community health centres provided $69 \%$ of recommended energy intake, while mean recommended dietary allowance met for protein was $51 \%$, calcium $18 \%$, iron $50 \%$, and fat $267 \%$. Conclusion: The recommendations specified in this paper would improve the nutritional status of all pregnant and lactating women availing the services in rural health facilities, which would go a long way in ensuring safe and healthy motherhood.
\end{abstract}

Keywords: institutional delivery, nutrition, pregnant women, lactating women, public health facility, weekly cycle menu

\section{INTRODUCTION}

The Janani Shishu Suraksha Karyakram (JSSK) is a government of India programme initiated in 2011 with free entitlements to benefit pregnant women who access government health facilities for their delivery and also to motivate those who still choose to deliver at their homes to opt for institutional delivery across all states of India. The free

\footnotetext{
*Corresponding author: Prof. Annie Kuruvilla

Department of Foods \& Nutrition, Faculty of Family \& Community Sciences

Maharaja Sayajirao University, Vadodara, Gujarat, India 390002

Tel:.91-982564653 E-mail: annie.kurvilla-fn@msubaroda.ac.in

doi: https: / / doi.org/10.31246/mjn-2021-0009
} 
entitlements include free and cashless delivery, free Caesarean section, free drugs and consumables, free diagnostics, free diet during the stay in the health institutions, free provision of blood in case of blood transfusion, exemption from user charges, free transport from home to health institutions, free transport between facilities in case of a referral, and free drop back from institutions to home after 48 hours stay (National Health Portal, 2015). The Indian Institute of Health Management and Research (IIHMR, 2012) conducted a study in Rajasthan and reported that $60 \%$ of mothers received free diet, whereas free diagnostic services were availed by $75 \%$ of them. The government of Gujarat extended the benefits of this scheme from neonates up to infants one year of age and up to 42 days postpartum for pregnant women.

Free diet is one of the main entitlements, but one which is not well taken care of with regards to quality and nutrients. Most of the women who register in these centres are from economically distressed background with moderate or severe malnutrition. All these conditions ultimately lead to maternal health problems and health issues in the newborns. If the beneficiaries are given proper nutritious diet during this crucial period, it would lead to safe delivery and good postnatal health. Numerous studies have been conducted on the awareness, utilisation, and out-of-pocket expenditure incurred in this programme, but no data is available on the nutrient content of the diets served, whether the recommended dietary allowances were met or fell short. A sedentary pregnant woman should consume 2500 kilocalories (kcal) per day, with 74 grams (g) protein, $30 \mathrm{~g}$ fat, 1200 milligrams (mg) calcium, and 21 mg iron (National Health Mission, 2018). This should be distributed in three main meals [two-thirds of the Recommended Dietary Allowance (RDA) distributed in three meals] and two snacks [one-third the RDA distributed in snacks]. The present study was aimed at evaluating the free diets served in different public health facilities and recommending two models of cyclic-weekly menu which could bridge the gap between the recommended dietary allowances prescribed by The Indian Council of Medical Research (Gopalan et al., 2011) guidelines for pregnant and lactating women and the actual diets served in the public health facilities.

\section{MATERIALS AND METHODS}

The study was a community cum facility based cross-sectional study, conducted in all the Community Health Centres (CHCs) of rural Vadodara district, in the state of Gujarat, India during the years 2019-2020. This study was approved by the Institutional Ethics Committee for human research under approval number: IECHR/2019/10, Department of Foods and Nutrition, The Maharaja Sayajirao University of Baroda, Vadodara, Gujarat, India. Rural Vadodara has eight blocks, in which there are ten CHCs. Written permission was sought from the Regional Deputy Director, Health and Medical services and from the Chief District Health Officer's (CDHO) office, Vadodara for conducting the study. At the beginning of data collection, before interviews were conducted, written consents were taken from all superintendents, head nurses, diet-aides-in-charge of the ten CHCs, and also from mothers who had then delivered and were using the health facilities. Weekly menu of the diet provided by the facilities was obtained using a descriptive, detailed questionnaire, which was made after an in-depth study of the service delivery of 
the programme in all health facilities. This tool (questionnaire) was pre-tested and modified several times until full details like the time of admission, time of delivery, date of discharge for normal and caesarean deliveries were incorporated, in order to study the extent of days the mothers were in the institution and availing diet provision.

The Maternal Health Division under the Ministry of Health and Family Welfare had published an operational guideline manual for diet provision under JSSK programme for all public health facilities in India (National Health Mission, 2018). The RDA for pregnant and lactating women (0-6 months) was used as the basis for developing the daily diet plans to provide food for mothers during their stay in the public health facilities, before and after delivery (National Health Mission, 2018). The portion sizes for one individual was weighed for each meal and the ingredients in each item were identified and quantified referring to the Indian Food Composition Tables (Longvah et al., 2017). Energy, protein, calcium, iron, and fat were calculated manually. Ten CHCs were serving two meals a day and since the menu was the same every day, random samples in triplicate were used to calculate the nutrients intake manually. Standard measuring cups and spoons were used to measure the exact serving sizes for each mother.

The collected primary data were analysed with the help of Microsoft Excel by using appropriate statistical tests. Diet consumption (energy and nutrients) per day and the cost of the daily menu were estimated (Tables 2 and 4, respectively). Mean and standard deviation $(S D)$ was calculated for all the nutrients in the diet (Table 2) and for the cost estimation for daily diet (Table 4).

\section{RESULTS}

For convenience of expression, the result section is divided into two sub-sections:

\section{a) Assessment of diet menu}

Out of the ten CHCs, seven had no kitchen facilities either due to lack of staff or infrastructure or less number of deliveries, so the meals were outsourced. Three of them were serving foods from their respective kitchens. Under the JSSK government programme, Indian rupees one hundred per person per day is allotted for the whole day's diet, which should include three main meals and two high energy snacks.

The mothers who availed the facilities in government health institutions were those near or below the poverty line and who were mostly malnourished. Illiteracy also accounted for not consuming nutritious diets and hence the onus lies on these institutions to make available nutritious diets and counsel the mothers to follow the same after discharge. In this study, it was observed that the diets prepared in the CHCs (three centres) using kitchen facilities and the institutions who had outsourced (seven centres) to caterers or restaurant owners, were not meeting the nutritional requirements as per the prescribed RDA. In one of the public health facilities, only one meal (lunch) was served, hence the lower intake of calories by mothers. In four of the health facilities, only two (lunch and dinner) meals were given. Only 50\% health facilities were serving three or more than three meals per day. The meals provided were neither balanced nor uniformed. All nutrients, except fat, were much lower than the recommended values. On average, only $53 \%$ of RDA for protein, 20\% RDA for calcium, and 52\% RDA for iron were met. The RDA for a pregnant 
Table 1. Recommended dietary allowance (RDA) for a sedentary pregnant mother for the entire day

\begin{tabular}{lccccc}
\hline & $\begin{array}{c}\text { Energy } \\
(\text { Kcal })\end{array}$ & $\begin{array}{c}\text { Protein } \\
(\mathrm{g})\end{array}$ & $\begin{array}{c}\text { Fat } \\
(\mathrm{g})\end{array}$ & $\begin{array}{c}\text { Calcium } \\
(\mathrm{mg})\end{array}$ & $\begin{array}{c}\text { Iron } \\
(\mathrm{mg})\end{array}$ \\
\hline $\begin{array}{l}\text { Recommended dietary allowance (RDA) } \\
\text { Meals - breakfast, lunch, dinner }\end{array}$ & 2500 & 74 & 30 & 1200 & 21 \\
$\quad$ & & & & & \\
$\quad$ main meals $(2 / 3$ of the RDA) & 1667 & 49 & 20 & 800 & 14 \\
$\quad$ Snacks-mid-morning, evening & & & & & \\
$\quad \begin{array}{l}\text { times snack (1/3 of the RDA) } \\
\text { Total }\end{array}$ & 833 & 25 & 10 & 400 & 7 \\
\hline
\end{tabular}

Source: Gopalan, Rama Sastri \& Balasubramanian (2011)

and lactating (0-6 month) sedentary mother in terms of energy is $2500 \mathrm{kcal}$ per day and the distribution is shown in Table 1. Ideally, three main meals in totality should give approximately 1667 kcal, with $49 \mathrm{~g}$ protein, $20 \mathrm{~g}$ fat, 800 $\mathrm{mg}$ calcium, and $14 \mathrm{mg}$ iron, while two snacks daily should give approximately $833 \mathrm{kcal}$ with $25 \mathrm{~g}$ protein, $10 \mathrm{~g}$ fat, 400 $\mathrm{mg}$ calcium, and $7 \mathrm{mg}$ iron.

\section{b) Development of the improved weekly cycle menu}

Comparing with the recommendation of three main meals (breakfast, lunch, dinner) which satisfies two-third of the RDA and two snacks (mid-morning \& evening tea) providing one-third the RDA, descriptive statistics of the existing daily RDA met per person in each public health facility in the rural blocks of Vadodara district were tabulated and presented in Table 2. Only five $\mathrm{CHCs}$ which were serving three meals or more a day were nearly meeting the energy requirements. Calcium and iron in the diets were dismal and these are some of the most important minerals needed during pregnancy, delivery and lactation phases, equally important to both mother and child.

Looking into the deficits of the nutrients in the diets, great efforts were made to develop a weekly cycle menu incorporating locally available vegetables and cereals, taking care of the requirements for macro- and micronutrients, yet keeping the cost at INR 100 per day per woman.

The majority of the people in Gujarat are vegetarians and hence recommendation for a weekly vegetarian menu for vaginal delivery is described in Table 3. Since it was not feasible to serve freshly cooked breakfast in the $\mathrm{CHCs}$ as per the existing conditions, hence, a practical weekly menu was also developed substituting freshly cooked breakfast with ready-to-eat high energy snacks that met the daily RDA (Table 4).

\section{DISCUSSION}

The JSSK programme has increased institutional deliveries since its launch. But in this study, it was seen that though free diet was given to all beneficiaries, the quality and nutrient content were dismal. The diets served to all mothers in the public health facilities in rural Vadodara was the general diet served to all patients who were admitted in the facility. This diet did not meet the dietary requirements for mothers whose nutritional needs were more. There was a shortage of kitchen facilities, proper infrastructure, diet counsellors and dietitians to prescribe and monitor the menu regularly. The caterers and restaurant owners who were entrusted with food delivery were either ignorant of the RDA or were not instructed 


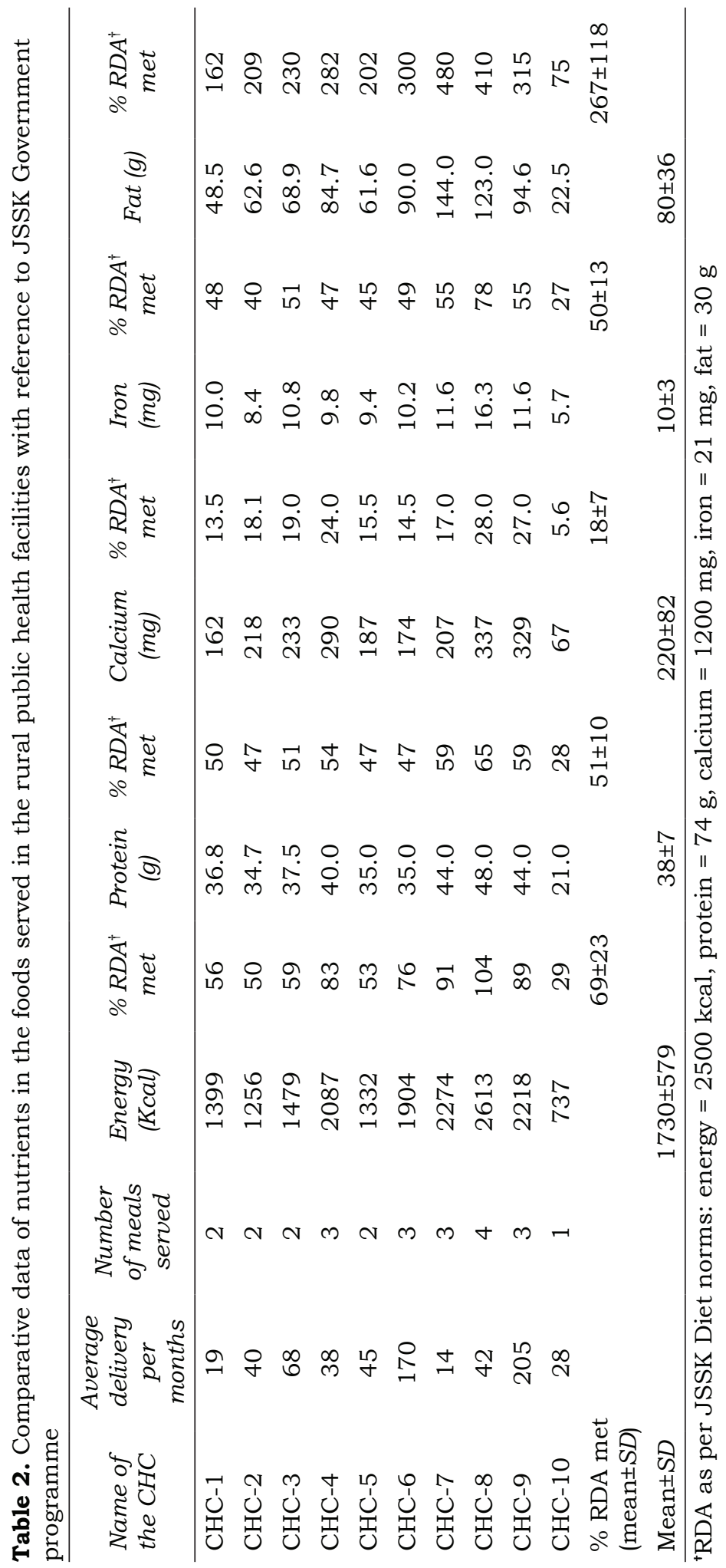




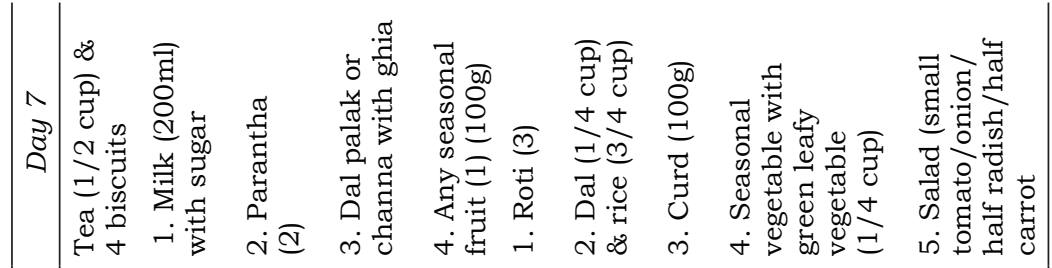

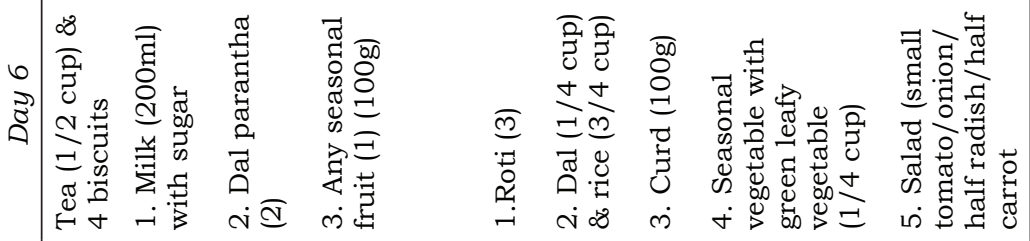

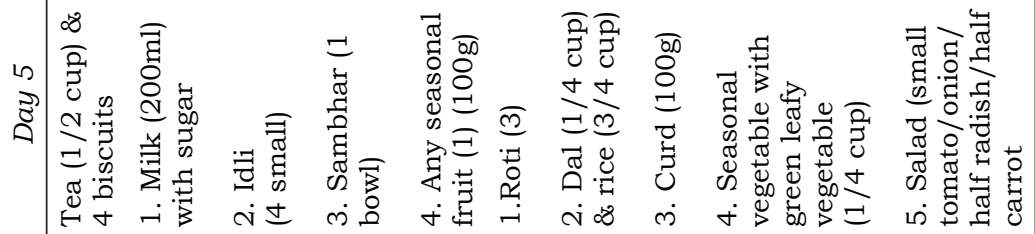

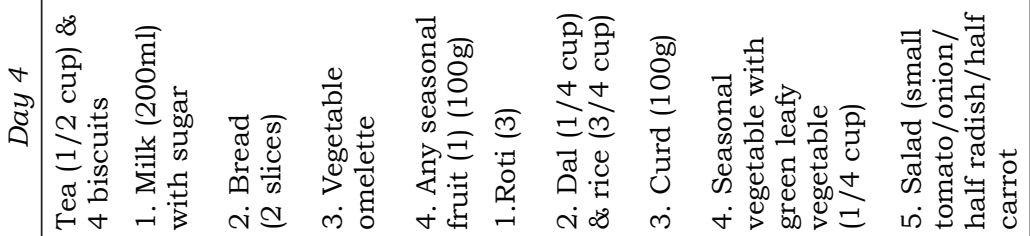

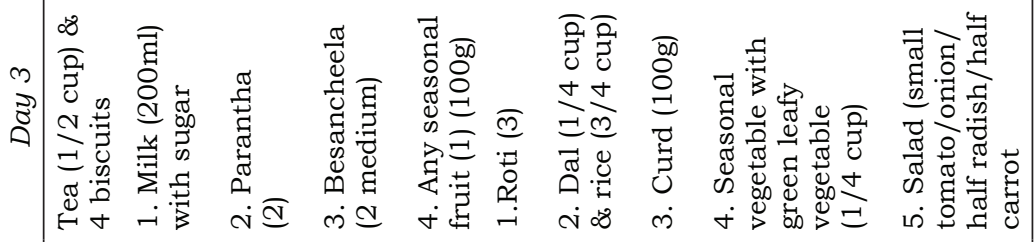

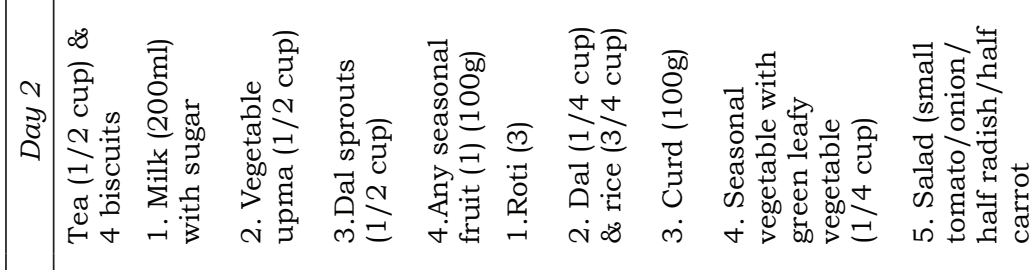

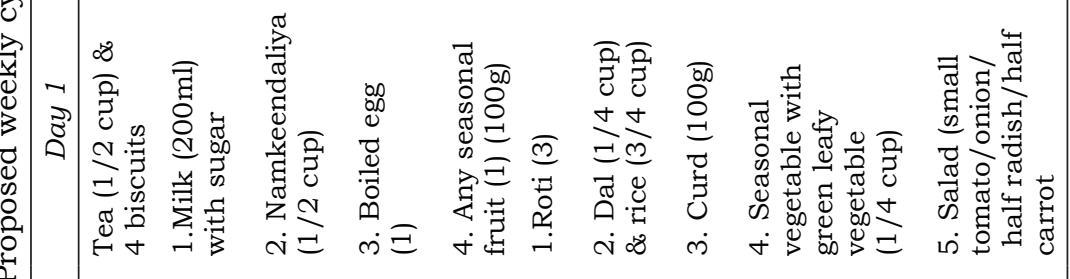

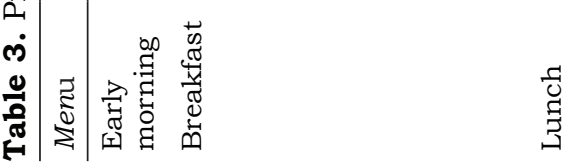




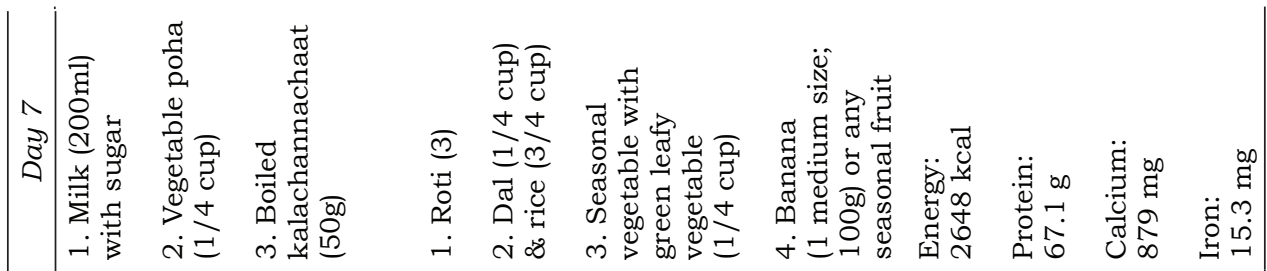

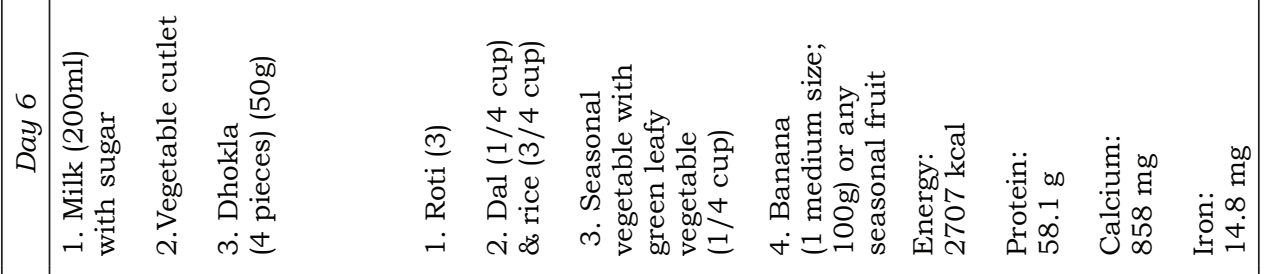

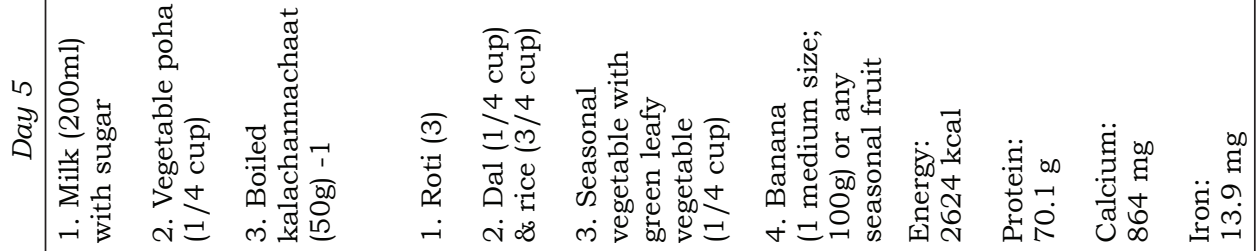

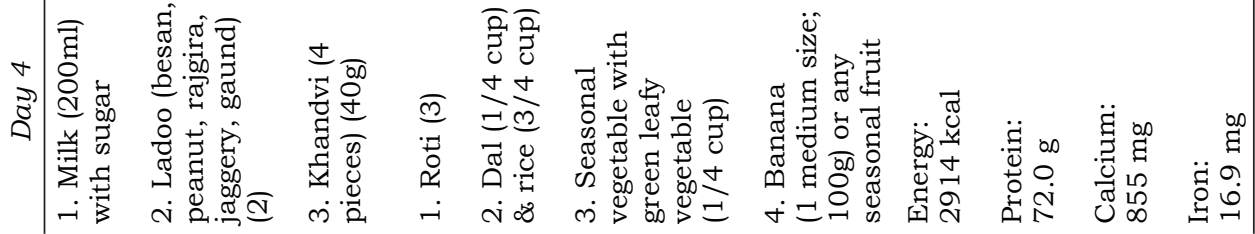

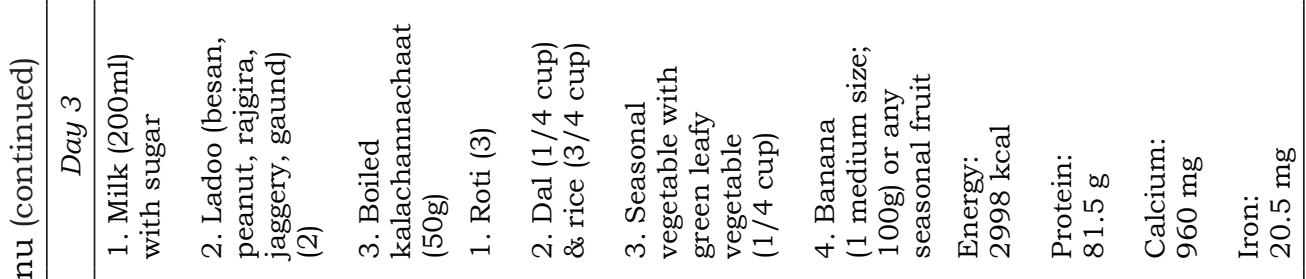

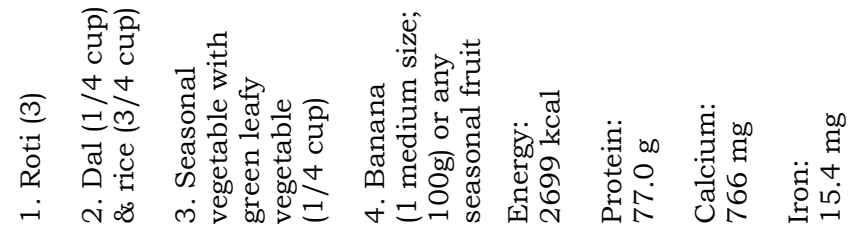




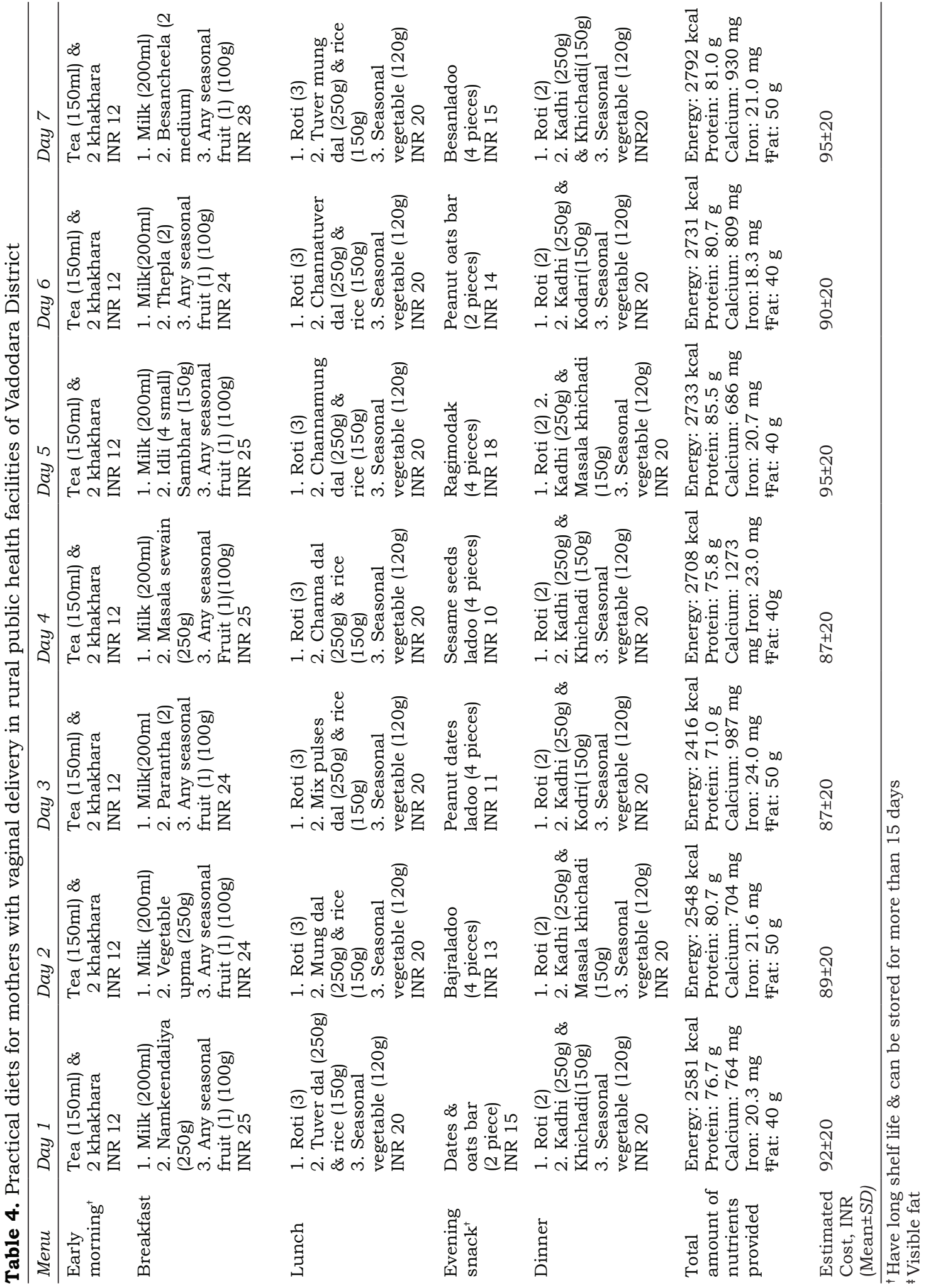


accordingly. The monetary allowance for a diet comprising of three fresh meals and two high energy snacks for a mother was only one hundred Indian rupees per day, which was insufficient, especially considering the inflation in food prices. The feasibility of serving fresh meals thrice a day was cumbersome and practically near to impossible. In a study by Sharma (2015), it was stated that INR 100 was not enough and he had also recommended to give nutritious freshly cooked meals and soups instead of raw eggs or bread when there is a lack of kitchen facility. Chaudhary et al. (2017) had reported that hot cooked meals were provided to all patients in general hospitals and tertiary care centres, but in periphery wards (Primary Health Centre/Community Health Centre) in rural Lakhan Majra, Haryana state, mothers were only given two dry packs of biscuits and a milk packet.

The fat intake exceeded the RDA, whereas calcium, iron, and protein requirements were difficult to meet because all the public health facilities followed a vegetarian diet, which did not have micronutrient-rich recipes, while a non-vegetarian diet was not feasible because the population were mainly vegetarians. Breastfeeding is associated with transfer of approximately 200 $\mathrm{mg} /$ day of calcium from mother to infant and studies have demonstrated that the increased calcium demand leads to mobilisation of this important mineral from the mother's skeleton, leading to transient reduction in bone mineral density (BMD) of the lumbar spine and femoral neck regions (4-7 $\%)$ during 3-6 months of lactation. The iron requirement during lactation is $25 \mathrm{mg} /$ day. The baby is born with a relatively larger reserve of iron since milk is not a good source of iron. Iron requirement during lactation is the sum of the mother's requirement and the iron required to make up for iron lost in breast milk. Since there is amenorrhea during lactation, the basal requirement for women is at 14 microgram $/ \mathrm{kg}$ (Srilakshmi, 2014). Unfortunately, foods rich in calcium (milk and milk products) and iron (green leafy vegetables) were unaffordable in the meagre amount of one hundred Indian rupees.

Only $51.6 \%$ of the women were aware about free diet provisions in JSSK in Marathawada, Maharashtra in a sample of one thousand women studied (Deshpande et al., 2016). A communitybased cross-sectional study conducted among 210 mothers in rural Bankura of West Bengal by Mondal et al. (2015) stated that the availability of free foods at the government health facilities was $59.5 \%$. Utilisation of services under JSSK for institutional deliveries in seven public sector facilities in Sirmaur District, Himachal Pradesh was studied by Tyagi et al. (2016) on 156 mothers. The mothers had to pay an extra amount ranging from INR 12 to 700 for their foods. Rupani et al. (2019) carried out a cross-sectional descriptive study in Sir Takhtsinhji hospital of Bhavnagar in Gujarat and found that $99.7 \%$ of the mothers were aware of the JSSK free diets provided during the stay, out of which $96.0 \%$ of mothers reported that they were offered free foods, whereas $16.0 \%$ of the mothers opted for homemade foods during their stay. To date, there are no studies reporting on the nutrient content analysis of the foods served through the JSSK programme. Hence, this present study has bridged the gap in explaining in detail the quantification of the nutrients in the diets and recommends modifications required in the dietary intake for mothers who avail these services in the public health facilities.

Proper utilisation of the JSSK grant will be successful if the functionaries are diligently working towards applying, receiving and monitoring the funds, 
inviting quotations for the best food delivery agents, well in advance at the beginning of each financial year, with the meticulous planning of diets especially for high risk mothers (diabetic and hypertensive). Diets for caesarean section delivery also calls for slight modifications of a semi-liquid diet for the initial two to three days post-operation. Every CHC should have a counsellor, preferably with a nutrition background, who would do continuous follow-up with mothers and would counsel them on different recipes for the required diet to be followed at home after discharge. More attention to maintaining diet registers and helping to reduce out-of-pocket expenses related to diet is also strongly suggested. The postnatal period is very critical for a mother and her newborn, and hospital stay is advised for three days for a normal vaginal delivery and seven days in case of a caesarean section. A mother who has just delivered her baby has increased nutrition demands and needs to be provided with a healthy balanced diet meeting the requirements to support her recuperation and for better milk production. A caesarean section delivery needs immediate nutritional care and attention. If dietary nutritional norms are clearly defined with operational guidelines, it would ensure quality postnatal care.

\section{CONCLUSION}

In this study, it was found that none of the CHCs had specific and separate diet provisions for the mothers. Functional kitchen was prevailing only in a few (three out of ten) public health facilities. Outsourcing of food preparation did not necessarily cater to the recommended daily allowances, unless food suppliers are trained or instructed according to the guidelines. The diets served in all the facilities were inadequate in macro- and micronutrients. There was no special diet provision for high risk pregnant mothers, such as those who were severely anaemic, hypertensive, or diabetic). It was found that only two fresh meals, namely lunch and dinner, were served in most of the public health facilities, which was the main reason for the deficit in nutrient intakes. Since serving freshly prepared foods more than twice was not feasible, ready-to-eat, caloriedense snacks meeting the required RDA per serving, with reasonable shelf life and which could be served in the early morning and evening was developed in this study.

Awareness needs to be created among health functionaries for proposing and utilising the diet grant under JSSK. The convergence of health departments and nutrition-related academic institutions is essential to strengthen JSSK implementation in all public health facilities. The recommendations suggested in this study, if accepted and abided, would improve maternal nutritional status before and after delivery; and if properly counselled, could be adopted by mothers during their lactation period too. In the long run, this can reduce maternal and infant mortality which is common in this population due to varied factors of poverty, illiteracy, blind beliefs, superstition etc.

\section{Acknowledgement}

We acknowledge the support of the Department of Foods \& Nutrition, The Maharaja Sayajirao University of Baroda, Vadodara, Gujarat and the University Grants Commission (UGC DSA SAP III) New Delhi, India for helping in carrying out this research work.

\section{Authors' contributions}

AK, principal investigator, conceptualised and designed the study, conducted final data analysis and interpretation, prepared the manuscript; KP, handled the survey, data collection, compilation and writing of the final manuscript; NP, conducted tool preparation, data coding and compilation, final data analysis and interpretation. 


\section{Conflict of interest}

The authors declared that there is no conflict of interest.

\section{References:}

Chaudhary S, Rohilla R, Kumar V \& Kumar S (2017). Evaluation of Janani Shishu Suraksha Karyakram scheme and out of pocket expenditure in a rural area of Northern India. $J$ Family Med Prim Care 6(3):477-81.

Deshpande S, Gadappa S, Pagare S, Dhaduti R \& Andurkar S (2016). Awareness regarding Janani Shishu Suraksha Karyakram among pregnant women of Marathawada, Maharashtra, India. Int $J$ Reprod Contracept Obstet Gynecol 5(6):1985-91.

Gopalan C, Rama Sastri B V, Balasubramanian S C (2011). Nutritive Value of Indian Foods, National Institute of Nutrition, Indian Council of Medical Research (ICMR), Hyderabad, India

IIHMR (2012). In: Janani Shishu Suraksha Karyakram-Report: Rajasthan. Indian Institute of Health Management \& Research

Longvah T, Ananthan R, Bhaskarachary K \& Venkaiah K (ed) (2017). Indian Food Composition Tables, National Institute of Nutrition (ICMR), Ministry of Health \& Family Welfare, Government of India, Hyderabad, India.

Mondal J, Mukhopadhyay DK, Mukhopadhayay S \& Sinhababu A (2015). Does Janani Shishu Suraksha Karyakram ensure cost-free institutional delivery? A cross-sectional study in rural Bankura of West Bengal, India. Indian $J$ Public Health 59(4):279-285
National Health Mission (2018). Dietary Norms: Operational Guidelines for State Programme Managers to be followed in Public Health Facilities. Maternal Health Division, Ministry of Health \& Family Welfare, Government of India. From: https://www.nhm.gov.in/New Updates_2018/NHM_Components/RMNCHA/ MH/Guidelines/JSSK_Final_English.pdf. [Retrieved December 23 2020].

National Health Portal (2015). In: Janani Shishu Suraksha Karyakaram (JSSK). National Health Portal 2015. From: https://www.nhp.gov.in/ janani-shishu-suraksha-karyakaram-jssk_pg. [Retrieved December 23 2020].

Rupani MP, Patel PM, Meena PR, Patel PP, Patel PA \& Paragda PK (2019). Regular antenatal care visits predict good knowledge among postnatal mothers regarding entitlements of Health Programs in Western India. Int $J$ Health Policy Manag 8(8):467-473.

Sharma S (2015). Janani Shishu Suraksha Karyakram and its repercussions on out of pocket expenditure. Int J Curr Res 7(9):2080820815.

Srilakshmi B (2014). Dietetics. New Age International Publishers, New Delhi. IBSN: 978-81-224-3500-9.135-141.

Tyagi U, Pattabi K \& Kaur P (2016). Utilization of services under Janani Shishu Suraksha Karyakram for institutional deliveries in the public sector facilities, Sirmaur District, Himachal Pradesh, India. Indian $J$ Community Med 41(1):65-8. 